\title{
The Cretaceous Oceanic Anoxic Events: new geochemical data from the Central Atlantic Ocean
}

\author{
BONACINA G. ${ }^{1 *}$, PREVIDE MASSARA E. ${ }^{2}$, SCOTTI \\ P. $^{2}$, VIAGGI P. ${ }^{2}$, PIVA A. $^{2}$, DIAMOND C. ${ }^{3}$, NEWBY \\ S. ${ }^{4}$, HUNG C. ${ }^{3}$, SANFILIPPO A. ${ }^{1}$, LYONS T.W. ${ }^{3}$, \\ OWENS J. D. ${ }^{4}$ \\ ${ }^{1}$ Dipartimento di Scienze della Terra e dell'Ambiente, Univ. of Pavia, \\ Via Ferrata 1a, 27100, Pavia, Italy \\ (*correspondence: greta.bonacina01@universitadipavia.it) \\ ${ }^{2}$ Eni S.p.A. Upstream Research and Technological Innovation, 20097 \\ San Donato Milanese, MI, Italy \\ ${ }^{3}$ Department of Earth and Planetary Sciences, University of \\ California, Riverside, CA 92521, USA \\ ${ }^{4}$ Department of Earth, Ocean and Atmospheric Science, Florida State \\ University, Tallahassee, FL 32306, USA
}

Cretaceous "Oceanic Anoxic Events" (OAEs) are global climatic perturbations marked by enhanced burial of marine and terrestrial organic matter with associated positive carbon isotope excursions $\left(\delta^{13} \mathrm{C}\right)$, global warming, elevated $p \mathrm{CO}_{2}$, enhanced weathering, increased hydrothermal activity, high sea level and changes in oceanic circulation. We present a geochemical study of a $\sim 1.8 \mathrm{~km}$-thick sedimentary section from the Central Atlantic Ocean spanning 50 Myrs from the early Aptian to early Campanian. This relatively continuous record captures four OAEs (OAE 1c-OAE 3). The aim is to characterize the local and ocean-scale redox conditions using traditional and novel techniques in a multi-proxy approach that includes organic contents, trace element data, iron speciation and thallium isotopes.

The section can be divided into three main intervals: the first spans from Early Aptian to OAE 1c and is characterized by local slightly reducing conditions. In the second interval, iron speciation data suggest that local anoxia developed from $\mathrm{OAE} 1 \mathrm{c}$ and persisted until after OAE 3. High $\mathrm{Fe}_{\mathrm{pyr}} / \mathrm{Fe}_{\mathrm{HR}}$ suggest locally sulfidic (euxinic) conditions from the onset of OAE 1d to OAE 3, with a climax during OAE 2. Expansion of euxinia during this interval led to a drawdown of Mo and $\mathrm{V}$ concentrations, reported also in previous work from other locations. The third interval, after OAE3 shows that local anoxia still persisted. Further, we go on to present thallium isotope data $\left(\varepsilon^{205} \mathrm{Tl}\right)$ documenting a long-term record of the waxing and waning of manganese-oxide burial on a global scale in this continuous record that provides a unique window to study an expanded Cretaceous record. 